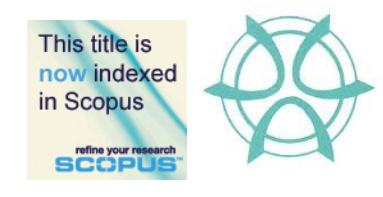

PLANNING MALAYSIA:

Journal of the Malaysian Institute of Planners

VOLUME 16 ISSUE 4 (2018), Page 81 - 91

\title{
TSUNAMI MODELLING PROCEDURES TO REFINE COASTAL ARCHITECTURAL DESIGN STRATEGIES AT KUALA MUDA
}

\author{
Jestin Nordin ${ }^{1}$, Andrew Charleson ${ }^{2} \&$ Morten Gjerde ${ }^{3}$ \\ ${ }^{1}$ School of Housing, Building and Planning \\ UNIVERSITI SAINS MALAYSIA \\ ${ }^{2 \& 3}$ School of Architecture \\ VICTORIA UNIVERSITY OF WELLINGTON, NEW ZEALAND
}

\begin{abstract}
This paper discusses the use of tsunami modelling to refine the strategies to be used in coastal architectural and planning design works in effort to minimize future tsunami impacts on the coastal buildings. The ability to recreate the characteristics of the 2004 Sumatran Tsunami waves and their impacts is the reason to use computer simulation as the main tool of this research project. The Cornell Multi-Grid Coupled Tsunami Model (COMCOT) programme has been chosen to generate a series of tsunami events onto a one-kilometre-square area of Kuala Muda (north-west of Peninsular Malaysia) coastal area. COMCOT is expected to help practitioners and researchers make the best possible designs for this tsunami-threatened near-beach area. It has the capability to simulate the entire lifespan of a tsunami inclusive of the characteristics and the behaviour of the waves once it inundates the design area. It creates an opportunity to better understand and evaluate the performance of proposed designs in order to achieve the most tsunami-resistant design. The 2004 Sumatran Tsunami waves are considered the worst case scenario this area will experience. Therefore, the waves generated act upon proposed settlement patterns and buildings which are iteratively modified to achieve minimum tsunami damage. COMCOT outputs are used to propose coastal architectural design strategies for present and future nearbeach area developments, especially in the north-western coast of Malaysia. The final Tsunami Responsive Architecture (TRA) design is intended to be culturally acceptable, and to be extended with or without modification to suit other coastal areas at risk of tsunami.
\end{abstract}

Keywords: tsunami response, COMCOT, coastal design, coastal architecture, coastal design strategies 
Jestin Nordin, Andrew Charleson \& Morten Gjerde

Tsunami Modelling Procedures to Refine Coastal Architectural Design Strategies at Kuala Muda

\section{IDENTIFIED MALAYSIAN TSUNAMI RISKS}

Recent research suggests that Malaysian coastal dwellings may be under threat from large tsunamis because of possible earthquakes in the region. The risk for Malaysia originates from far-field tsunami sources originating from neighbouring countries. In this introduction section, we briefly discuss and outline the threats of future tsunami to Malaysia both for West Malaysia (Peninsular) and East Malaysia (Borneo Island). However, this research focuses only the north-western coastal area of Peninsular Malaysia, particularly the Kuala Muda, in Kedah.

Along the northern Peninsular Malaysia coast, tsunami risk comes from the Indian Ocean (Andaman and Nicobar Islands) (Okal \& Synolakis, 2008). Research have also shown that the north-western coastal area of Peninsular Malaysia will be the first to be impacted by a future tsunami generated by a submarine earthquake originating from the Sumatra-Andaman fault (Ismail et al., 2012; Teh, Koh, Moh, DeAngelis, \& Jiang, 2011). The eastern coast of Peninsular Malaysia and the Sabah and Sarawak region will be affected by the Manila Trench near the Philippines (Teh et al., 2011), and Cotabato and North Sulawesi (Raj, 2007). Additionally, the Sulawesi Trench could also impose future tsunami threat to Sabah ("Tsunami can reach Sabah in 30 mins", 2018).

Scientists cannot predict when an earthquake may happen again in this area. The $2004 \mathrm{Mw} 9.3$ earthquake already released some of the strain along the Sumatran plate boundaries. However strain in other areas is still building up and scientist such as Stein suggests that the segments to the south of the fault slip can break at any time generating another tsunami (Schirber, 2005).

Working on numerical tsunami simulation, Okal and Synolakis (2008) note that if an earthquake occurs north of Andaman and Myanmar, a huge tsunami will occur and inundate the coastal areas along the Strait of Melaka and to Singapore. They suggest the need of researching the possibility of the inundation to this area, and the impact the tsunami may create to coastal structures (Okal \& Synolakis, 2008; Johar, Majid, Jaffar, \& Yahya, 2013). This shows that future earthquakes in these areas will likely generate tsunamis that impact the northwestern Malaysia. Okal and Synolakis (2008) concluded that the Strait of Melaka (Figure 1) would be safe from tsunami such as the south Sumatran Tsunami. However, coastal areas in the straits area would be in greater danger than for the 2004 event if a tsunami originates from the Andaman and Myanmar region earthquake (Hock, Su, Lee, \& Zakaria, 2009; Okal \& Synolakis, 2008; Teh et al., 2011).

Additionally, researchers have also uncovered evidence of tsunamis occurring hundreds of years ago in the northern part of Phra Thong Island, Phuket, Thailand (Tan, 2008) as indicated by the triangle in Figure 1. Researchers have found layers of sand that could be dated from 600 to 700 years ago, which is evidence of a tsunami had struck Thailand before 2004, and possibly the north-western coast of Peninsular Malaysia as well. 
PLANNING MALAYSIA

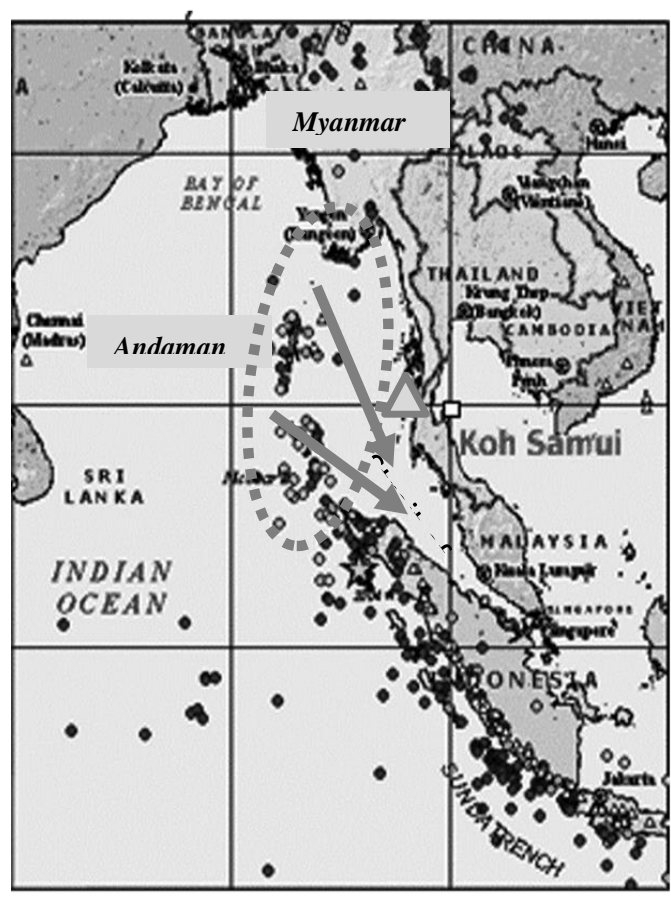

Figure 1: The Strait of Melaka will be in danger from the tsunamis originating from Andaman and Myanmar submarine earthquakes.

Source: www.googleimages.com

Even though the north-western coast of Peninsular Malaysia is only threatened by far-field tsunamis originating from neighbouring countries such as Indonesia, India, and Myanmar, the level of destruction is quite severe. The survey findings of the maximum tsunami run-up heights and the depth of inundations will be used as the 'design level tsunami' for the Kuala Muda coastal area. Therefore, the Tsunami Responsive Architecture (TRA) designs proposed in this article will be based on the characteristics of the 2004 Sumatran Tsunami as the 'design level tsunami'.

\section{COMPUTERISED TSUNAMI SIMULATION MODELLING}

This section describes how a series of working designs were tested using a computerised tsunami simulation programme named, COMCOT (Cornell Multigrid Coupled Tsunami Model) - Version 1.7 (Liu, 2007). Computer simulation aided in further developing the overall proposed TRA coastal master plan. At an earlier stage of the TRA design work, the design was developed on the basis of best-practice recommendations from the literature. It also integrates the needs of 
Jestin Nordin, Andrew Charleson \& Morten Gjerde

Tsunami Modelling Procedures to Refine Coastal Architectural Design Strategies at Kuala Muda

the coastal people of Kuala Muda (the end-users), which were identified during data collection surveys.

There are several other tsunami simulations on the market such as TsunAWI (Harig, Chaeroni, Pranowo, \& Behrens, 2008), TUNA (Koh, 2007), MOST (Pacific Marine Environmental Laboratory, 2006), ANUGA (Nielsen, Sexton, Gray, \& Bartzis, 2005), TUNAMI (Immamura, 1995), INGV of the Instituto Nazionale Geofoscia e Vulcano, Italy and DELFT-3D of the Delft Hydraulics, the Netherlands. However, one of the main reasons COMCOT was used in this research was because COMCOT has been calibrated and is widely used by researchers to simulate past tsunami events. Some of the simulation projects using COMCOT were the re-creation of the 1960 Chilean earthquake tsunami, the 1992 Flores Island tsunami, the 2003 Algerian tsunami and the 2004 Sumatran tsunami. Therefore, COMCOT was seen as an appropriate tool to test the TRA designs options of this research project.

The main features of COMCOT are (COMCOT - A tsunami modelling package, 2011):

i. COMCOT is capable of simulating the entire lifespan of a tsunami, from its generation, propagation and run-up/rundown in coastal regions;

ii. COMCOT can generate tsunami waves via an incident wave maker, fault model, landslide, or even customized profile;

iii. COMCOT has a flexible nested grid setup which allows for the balance between accuracy and efficiency;

iv. COMCOT can help refine TRA designs and in making strategic decisions.

Although physical modelling was initially considered during the initial setup for testing the TRA designs, COMCOT was finally selected. The decision was made on the basis of cost; computer simulation is less expensive than the setting up of a physical model.

\section{OVERVIEW OF COMCOT MODELLING}

Before starting with the COMCOT operation, several issues were considered to ensure the experimental work can be successful. These are questions of what to model, why, and how many designs to model and test, and how to get the best from COMCOT.

\section{What to Model?}

COMCOT is needed to model several tsunamis that are likely to strike the Malaysia north-western coastal area, especially Kuala Muda. COMCOT was used to regenerate the 2004 Sumatran Tsunami. The proposed TRA designs was then tested against that, because this is the worst case scenario that are dangerous 
PLANNING MALAYSIA

Journal of the Malaysia Institute of Planners (2018)

for the Strait of Melaka's coastal areas (Ismail, Wahab, \& Ibrahim, 2009; Okal \& Synolakis, 2008).

\section{Why Model This Particular Area?}

Kuala Muda is just one fishing village from hundreds of typical Malaysian traditional fishing communities bordering the Malacca Straits. However, it needs to be protected from future tsunamis since the threats are real (Ismail, 2010; Okal $\&$ Synolakis, 2008; Khor (2005). The selection of a one-kilometre square coastal area was then used as a tsunami-resistant case-study to be implemented elsewhere (with some adjustment, according to the local future predicted tsunami characteristics) in Malaysia.

\section{How Many Models to be Generated and Tested?}

The proposed TRA designs were tested several times against the tsunami waves generated by COMCOT. The first initial TRA design incorporated mostly suggestions of the 'best-practices' tsunami resistant design from the literature, coastal construction manuals, and also construction and planning guidelines such as the FEMA P-55 (Coastal Construction Manual), FEMA 499 (Home Builder's Guide to Coastal Construction), and FEMA 646A (Local Community Official Guide to Vertical Evacuation from Tsunamis), just to name a few. Iteration on the design was continuously done only until the design could be evaluated as positively responsive enough to reduce tsunami forces upon it.

\section{What Aspects of the TRA Designs will be Tested?}

A series of building layout and building designs was analysed against generated tsunami waves. The overall performance of the proposed master layout, i.e. arrangement and orientation of the buildings, elevations and the buildings' forms was investigated and analysed. To ensure that the final TRA design will be tsunami-responsive enough, all critical design aspects were thoroughly inspected.

In every test, the waves flowing through the model i.e. the TRA design layout and building designs were analysed. The analyses investigated the heights of the run-up, the inundation, the velocity of the flow, the terminal height, and the hydraulic forces impacting the surfaces of buildings, and the effectiveness of the overall master layout. The results were used to iterate improvements in the design, so as to meet the TRA design objectives as closely as possible.

\section{COMCOT MODELLING PROCESSES}

Setting up numerical simulation datasets for testing was a very time-consuming task with so many datasets needing to be prepared in fine detail. First, a bathymetry map of the near-shore area of Kuala Muda (MAL 565: Ko Tarutao Pulau Pinang) as well as the topography map of the researched coastal area were 
Jestin Nordin, Andrew Charleson \& Morten Gjerde

Tsunami Modelling Procedures to Refine Coastal Architectural Design Strategies at Kuala Muda

digitized. Since both maps acquired were hard-copy, Golden Software Surfer 10.0 (Software, 2011) was used to enable the maps to be digitized (Figure 2). Surfer 10.0 helped produce a highly detailed version of the seabed surfaces and the topographic characteristics of Kuala Muda. Highly detailed datasets are needed to produce accurate and reliable output from COMCOT.

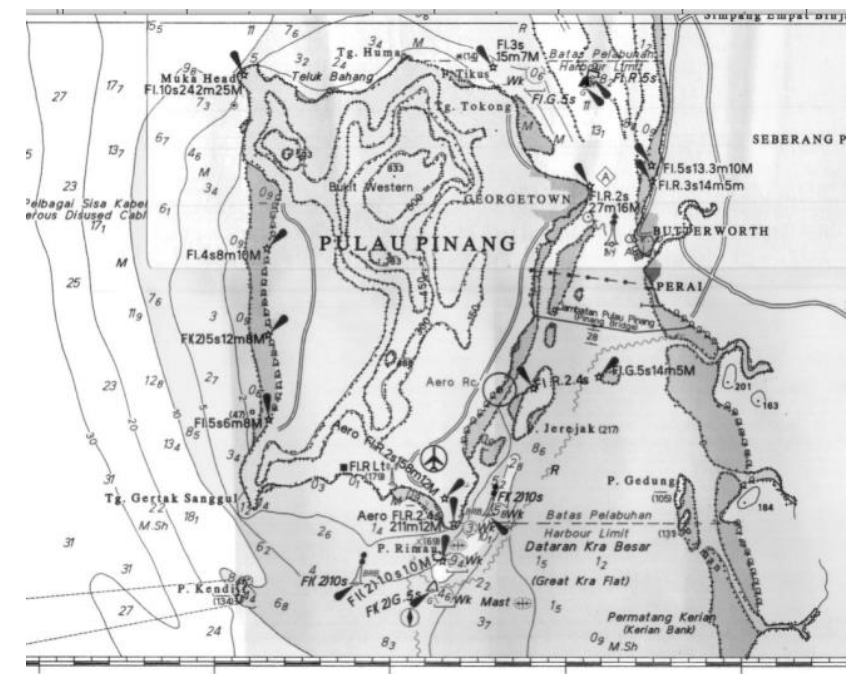

Figure 2: Figure shows the level of detailing needed to produce a high quality datasets to work in COMCOT. Source: Nordin (2015)

Surfer 10.0 produces .dat file format. These files were then converted to .txt file format using the Microsoft Excel or Notepad. The .txt files were later inserted into Global Mapper V12 (LLC, 2009) software needed to produce the three-dimensional surface profiles of the research area.

Five layers of datasets were prepared and set in layers in COMCOT; Grid Layer 1 was set with 1000m grid resolution, Grid Layer $2-500 \mathrm{~m}$, Grid Layer 3 - 20m, Grid layer 4-5m, and Grid Layer 5-1m. Grid Layer 1 represents the biggest coverage dataset with the widest grid resolution. A coarser dataset of bathymetry and topography of wider Indian Ocean and Malacca Strait bathymetry is downloadable from ETOPO1. ETOPO1 is a model of the surface of the world which contains both land topography and the ocean bathymetry in 1 arc-minute (Amante \& Eakins, 2009) (1 arc-minute equals to $1 / 60$ degree). The topography and nearshore bathymetry of Kuala Muda (digitized datasets) were the finest datasets needed for this tsunami inundation modelling purposes. After the bathymetry and topographic surfaces modelling completed, the TRA design layout plan was then digitized. 
PLANNING MALAYSIA

Journal of the Malaysia Institute of Planners (2018)

The fully developed topography and bathymetry datasets include the finished digitized TRA design, which was then converted into .xyz file formats to create the full set of surface data needed. The compiled datasets, i.e. bathymetry and topography surfaces, earthquake fault models, and the TRA design (all converted as .xyz files format) were inserted into COMCOT. This is the stage where the TRA designs were tested.

The TRA design undergwent some iterations after each test run in COMCOT. The behaviour of the waves that inundate the coastal land area and the buildings were then analysed. The retreating waves were also considered. Several design iterations were analysed to see aspects of the TRA designs which needed to be improved. Designs that fail to attain intended TRA design objectives were improved. Testing in COMCOT was repeated until the best and most responsive TRA design against tsunami waves was achieved. Figure 3 shows the overall process that involves COMCOT to test the TRA designs.

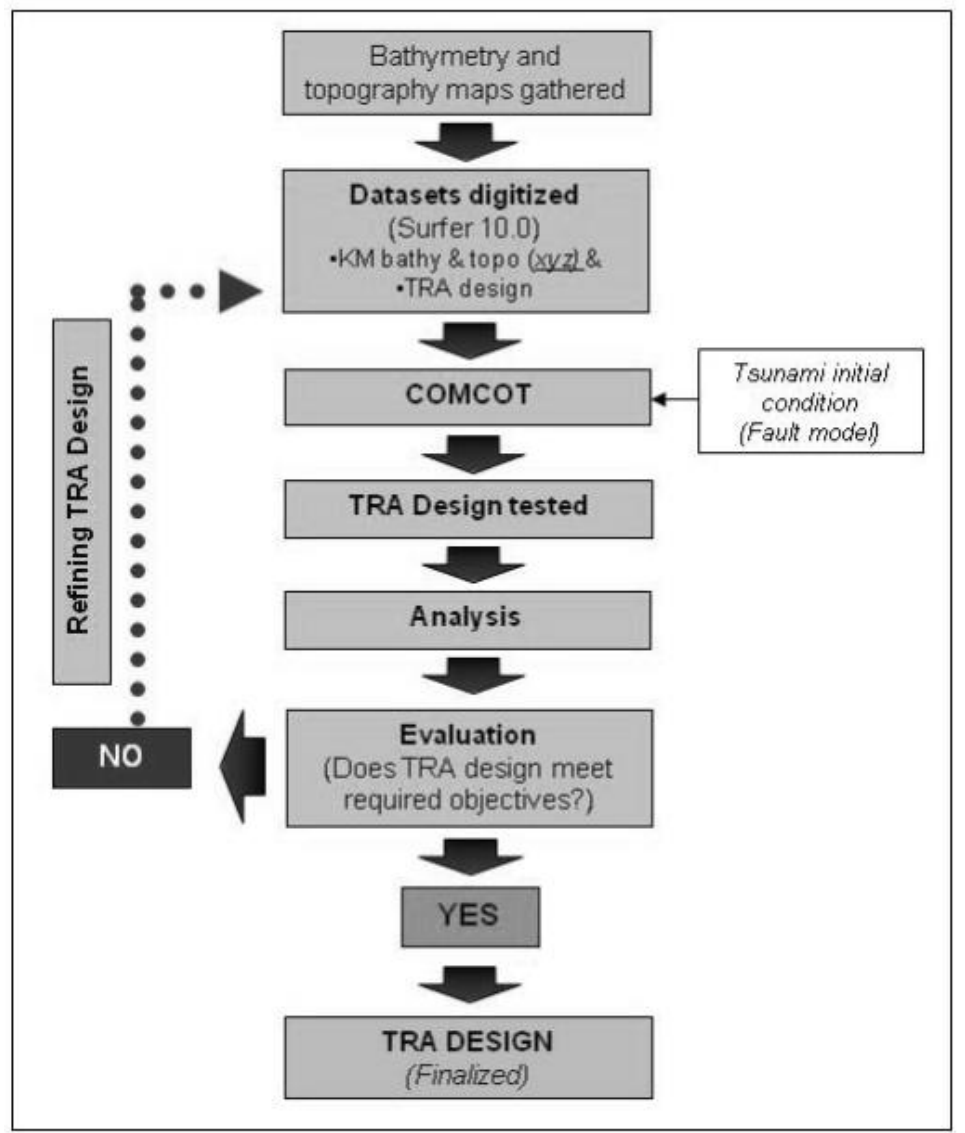

Figure 3: COMCOT work process 
Jestin Nordin, Andrew Charleson \& Morten Gjerde

Tsunami Modelling Procedures to Refine Coastal Architectural Design Strategies at Kuala Muda

\section{ADVANTAGES AND LIMITATIONS OF COMCOT}

Every programme or application has its limitations, including COMCOT. In this section, the advantages of using computer modelling against physical modelling are discussed.

The first advantage of using the COMCOT is the ability to run test many times, and for the researcher to make faster adjustments to the datasets compared to using a physical model. COMCOT is capable of generating the maximum value of inundation depth, velocity of the waves, hydrodynamic forces, and also the curve of the tsunami arrival period (Wijetunge, Wang, \& Liu, 2008). This information can be recorded graphically and will help to study and understand the waves' behaviour when they hit the TRA design model.

COMCOT can model the tsunami run-up and also retreating tsunami waves (COMCOT - A tsunami modelling package, 2011). These features enable better analyses of the incoming waves' movements onto the coastal area and around the buildings and structures, and also the impact of retreating waves.

COMCOT has two fault models. First, from Mansinha \& Smylie's theory and the second based upon Okada's theory (COMCOT - A tsunami modelling package, 2011; Wang 2011). Both are based on the input of earthquake parameters to calculate the displacement of the seafloor. Okada's theory is an extension of Mansinha \& Smylie's theory (COMCOT - A tsunami modelling package, 2011). These models enable a submarine earthquake to be created from anywhere along an identified existing fault slip in the region being considered.

Computer modelling is more cost effective to run. A physical model using wave-flumes or a wave-basin needs far more resources than are available. Computer simulation can also be operated from anywhere in the world, and not fixed in one place.

Regarding limitations of COMCOT, there are some issues to be taken care of by the researchers. Careful input of data is needed to avoid any mistakes during the mapping and data digitalizing process. The data (.dat formats) produced by the Surfer 10.0 need to be checked carefully before converting the whole datasets to a .txt file. Any mistake in processing these datasets will generate inaccurate results.

COMCOT works three-dimensionally, however it can only read the input of two-dimensional models. In other words, COMCOT cannot read or give information for better 3D building forms, except a solid geometric pattern. For example, COMCOT only reads and gives information on what is happening to the columns' surfaces of buildings designed with elevated first floors, i.e. no walls at ground floor, but no information for the walls at the first floor.

Another issue is that every building and structure designed is assumed to be very strong and not collapse in the simulations. This occurs because COMCOT cannot simulate the destruction of those buildings by the waves, but will shows the diffraction of the waves when they hit the structures. The simulation's output 
will need inspection, and decisions to iterate TRA design were based on manually calculated structural strengths against hydro-dynamic forces.

Debris transportation is not simulated in COMCOT. This is another disadvantage of this simulation programme. Since possible density of debris could and will change dramatically in real-time i.e. not a fixed hazard, it is too difficult to simulate this condition. Debris transportation however was ignored in this research.

\section{SIMULATION RESULT}

Based on the output of COMCOT simulation exercises shown in Figure 4, the findings concluded that the proposed final TRA design layout shown promising effectiveness to help reduce the damage to the coastal properties (specially to the 'intended shielded area' of existing weaker coastal structures, i.e. the nonengineered kampong houses) in Kuala Muda where the velocity of waves is reduced significantly by $43 \%$ to $67 \%$; tsunami run-up heights reduced by $14 \%$ to 100\%; and the distance of inundations also is reduced by $65 \%$ to $90 \%$ (Nordin, 2015).
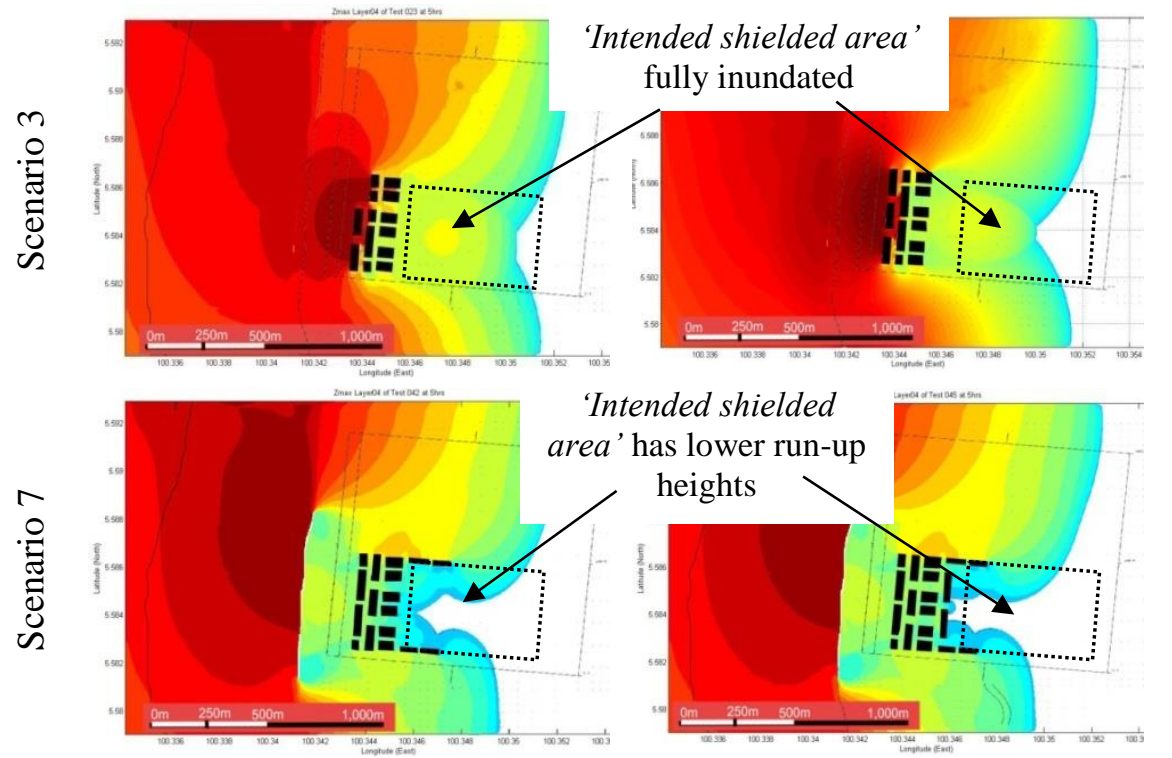

'Intended shielded ea' has lower run-up

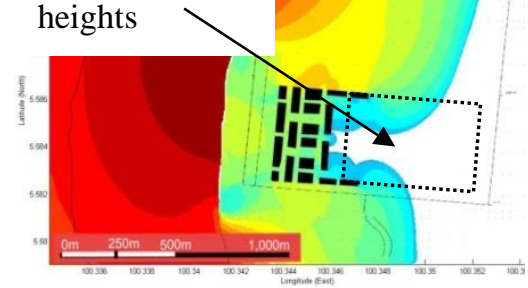

Figure 4: COMCOT simulation assisted in modelling the strategies to protect the 'intended shielded area' at Kuala Muda, Kedah, Malaysia. Source: Nordin (2015) 
Jestin Nordin, Andrew Charleson \& Morten Gjerde

Tsunami Modelling Procedures to Refine Coastal Architectural Design Strategies at Kuala Muda

\section{CONCLUSION}

COMCOT is a vital tool needed because of its ability to regenerate previous tsunami events and also to generate predicted ones instead of using a physical model. The decision was also made because computer simulation is not only cheaper to run than setting up a physical model, but it also enable researcher to study the overall performance of the proposed TRA coastal design as beneficial, hence a better informed coastal architectural design decision can be made to reduce casualties of both human and properties.

\section{ACKNOWLEDGEMENT}

Countless appreciations to the Universiti Sains Malaysia (USM) Short-Term Grant No. 6313328. Also, thanks to the New Zealand Geological and Nuclear Science (GNS) scientists especially to Dr. Xiaoming Wang (for the setting up of the COMCOT simulation, and the technical guides provided) and Dr. Gegar Prasetya (who has been so helpful during the earlier stage of dataset preparation). The authors also would like to thank the Ministry of Higher Education Malaysia (MoHE) and USM-ASTS for the financial assistance provided to finish this research project.

\section{REFERENCES}

Amante, C., \& Eakins, B. W. (2009). ETOPOI 1 Arc-Minute Global Relief Model. Available at http://www.ngdc.noaa.gov/mgg/global/global.html

COMCOT - A tsunami modelling package. (2011). Retrieved from http://ceeserver.cee.cornell.edu/pll-group/comcot.htm

Harig, S., Chaeroni, Pranowo, W. S., \& Behrens, J. (2008). Tsunami simulations on several scales. Ocean Dynamics, 58(5-6), 429-440.

Hock, L. K. (2007). TUNA - tsunami model. Pulau Pinang: Universiti Sains Malaysia.

Hock, L. K., Su, Y. T., Lee, M. K., \& Zakaria, N. A. H (2009). Simulation of future Andaman Tsunami into Straits of Malacca by TUNA. Journal of Earthquake and Tsunami, 3(2), 89-100.

Immamura, F. (1995). TUNAMI-N1. Tohoku, Japan: Tohoku University, Japan.

Ismail, H., Wahab, A. K. A., \& Ibrahim. (2009, November). Numerical experiments on tsunami propagation into the Straits of Melaka: Focus on the N-W Coast of Peninsular Malaysia. South China Sea Tsunami Workshop. November 3-5, 2009, Penang, Malaysia.

Ismail, H. (2010). Tsunami vulnerability assessment technique for the north-west coast of Peninsular Malaysia. Petaling Jaya: (n.p).

Ismail, H., Abdul Wahab, A. K., Mohd Amin, M. F., Mohd Yunus, M. Z., Jaffar Sidek, F., \& Esfandier, J. B. (2012). A 3-tier tsunami vulnerability assessment technique for the north-west coast of Peninsular Malaysia. Journal of Natural Hazards, 63, 549-573.

Johar, F., Majid, M. R., Jaffar, A. R., \& Yahya, A. S. (2013). Seismic microzonation for Banda Aceh city planning. Planning Malaysia, 2, 137-162. 
Khor, M. (2005). Save the mangroves to fight tsunamis. Third World Network, (Climate Change). Retrieved from http://www.twn.my/title2/gtrends39.htm

Liu, P. L.-F. (2007). Cornell Multi-grid Coupled Tsunami Model - COMCOT. Retrieved from http://223.4.213.26/archive/tsunami/cornell/comcot_link.htm

Nielsen, O., Sexton, J., Gray, D., \& Bartzis, N. (2005). ANUGA. Canberra, Australia: Geoscience Australia. Retrieved from http://www.ga.gov.au/ausgeonews/ausgeonews200609/modelling.jsp

Nordin, J. (2015). Tsunami responsive architecture: Reducing vulnerability along the North-western Coast of Malaysia (Doctoral dissertation). Victoria University of Wellington, Wellington, New Zealand.

Okal, E. A., \& Synolakis, C. E. (2008). Far-field tsunami hazard from mega-thrust earthquakes in the Indian Ocean. Geophysical Journal International, 172, 9951015.

Pacific Marine Environmental Laboratory (2006). Method of Splitting Tsunami (MOST). Seattle, USA: National Oceanic and Atmospheric Administration. Retrieved from http://www.prsn.uprm.edu/Spanish/tsunami/media/MOST_manual.pdf

Raj, J. K. (2007). Tsunami threats to coastal areas of Sabah, East Malaysia. Geological Society of Malaysia. Bulletin 53, 51-57.

Schirber, M. (2005, February 8). Tsunami earthquake three times larger than first thought. Retrieved from http://www.livescience.com/environment/050208_ sumatra_quake.html

Tan, E. L. (2008, October 30). Mega-tsunami hit Southeast Asia 700 years ago. Reuters. Retrieved from https://www.reuters.com/article/us-tsunami-asia-history/megatsunami-hit-southeast-asia-700-years-ago-idUSTRE49S7EX20081029

Teh, S. Y., Koh, H. L., Moh, Y. T., DeAngelis, D. L., \& Jiang, J. (2011). Tsunami risk mapping simulation for Malaysia. Disaster Management and Human Health Risk II, 119, 3-14.

Tsunami can reach Sabah in 30 mins, says report (2018, October 17). Retrieved from https://www.edgeprop.my/content/1434775/tsunami-can-reach-sabah-30-minssays-report

Wang, X. (2011). User manual of COMCOT - a tsunami generation propagation and runup model. GNS Science Report, 1-102.

Wijetunge, J. J., Wang, X., \& Liu, P. L.-F. (2008). Indian Ocean Tsunami on 26 December 2004: Numerical modeling of inundation in three cities on the south coast of Sri Lanka. Journal of Earthquake and Tsunami, 2(2), 133-155. doi:10.1142/S1793431108000293

Received: $1^{\text {st }}$ June 2018. Accepted: $1^{\text {st }}$ December 2018 